\title{
Robotics rehabilitation of the elbow based on surface electromyography signals
}

\author{
Monica Tiboni, Alberto Borboni $\mathbb{D}$, Rodolfo Faglia and Nicola Pellegrini
}

\begin{abstract}
Physical rehabilitation based on robotic systems has the potential to cover the patient's need of improvement of upper extremity functionalities. In this article, the state of the art of resistant and assistive upper limb exoskeleton robots and their control are thoroughly investigated. Afterward, a single-degree-of-freedom exoskeleton matching the elbowforearm has been advanced to grant a valid rehabilitation therapy for persons with physical disability of upper limb motion. The authors have focused on the control system based on the use of electromyography signals as an input to drive the joint movement and manage the robotics arm. The correlation analysis between surface electromyography signal and the force exerted by the subject was studied in objects' grasping tests with the purpose of validating the methodology. The authors developed an innovative surface electromyography force-based active control that adjusts the force exerted by the device during rehabilitation. The control was validated by an experimental campaign on healthy subjects simulating disease on an arm, with positive results that confirm the proposed solution and that open the way to future researches.
\end{abstract}

\section{Keywords}

Robotics, rehabilitation, force control, surface electromyography signals, upper limb motion

Date received: 31 July 2017; accepted: 19 December 2017

Handling Editor: Tadeusz Mikolajczyk

\section{Introduction}

Robotics for human devices can be classified into two clusters. The first class of orthoses is exterior with respect to the subject limb. The system offers all the power necessary to move a patient to the required position $^{1-5}$ without taking into consideration the joint movements of limb. The second cluster refers to exoskeleton robots, the actual trend, worn by the patient. In these devices, mechanical joints of the orthosis correspond to the human joints of the limbs, sustaining them in the movement. ${ }^{6}$ Exoskeleton machines are widely explored in the fields of human motion recovery, ${ }^{7-12}$ assistive automation, ${ }^{13-18}$ human power amplification, ${ }^{19}$ deficiency appraisal, ${ }^{1}$ resistance trainings, ${ }^{20}$ and haptic collaboration in tele-operated and simulated settings. ${ }^{16,21}$ Their increasing importance was driven by their potential in improving the quality of life for the individuals who need external assistance.

Exoskeleton robots for the upper limb are categorized into numerous ways in view of the features' machine-driven and regulator strategies. In Table 1, the rehabilitation devices electrically actuated are classified by a concise comparison. The hardware mechanisms are associated and organized with respect to their active degree of freedom (DOF), form of actuators, power

Department of Mechanical and Industrial Engineering, University of Brescia, Brescia, Italy

\section{Corresponding author:}

Alberto Borboni, Department of Mechanical and Industrial Engineering, University of Brescia, Via Branze, 38 - 25123 Brescia, Italy.

Email: alberto.borboni@unibs.it 


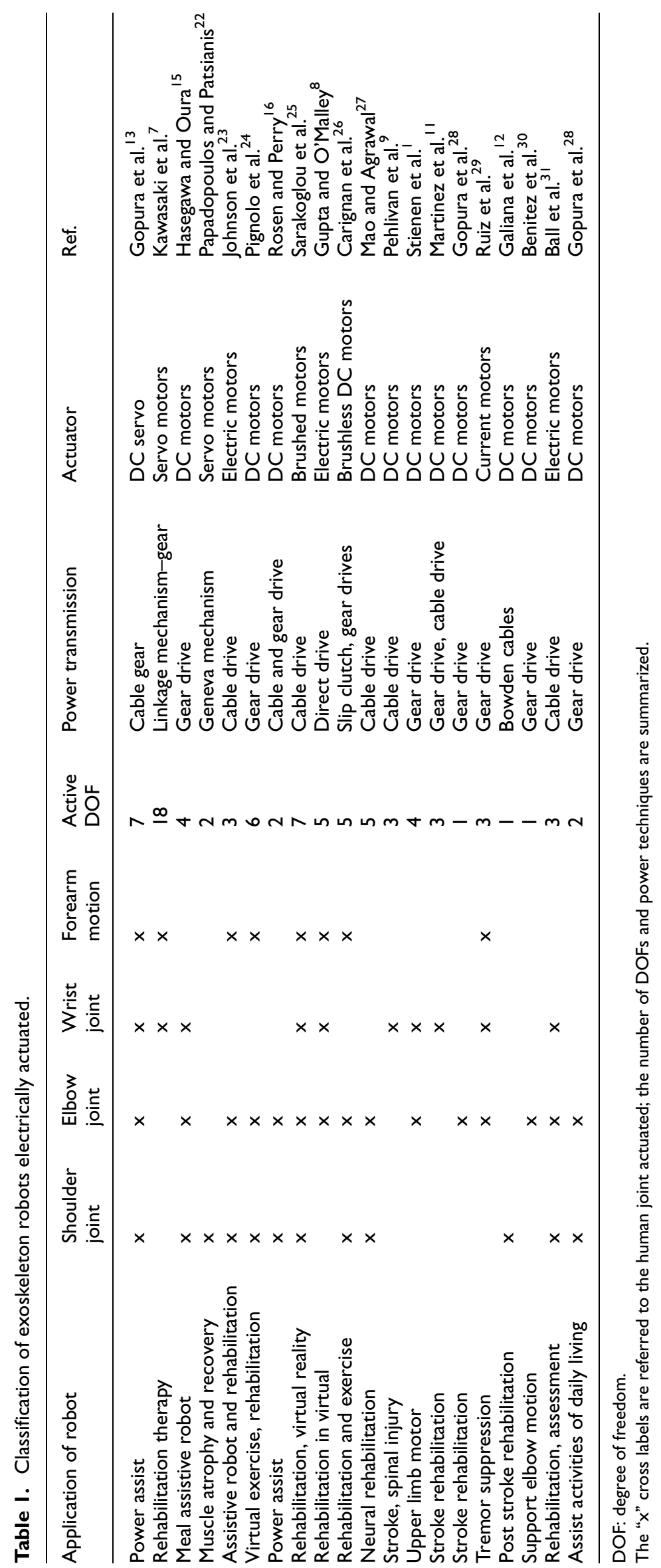


technique, and request field of the machine. Majority of exoskeleton structures are based on serial-wise construction while other machines have accepted united serial/parallel linkage arrangements. ${ }^{32}$ Among the compared hardware systems, about $70 \%$ of the devices use electrically powered motor for actuation, ${ }^{28}$ in the $30 \%$ remaining devices, $20 \%$ use pneumatic approaches, $7 \%$ use hydraulic actuation, and $3 \%$ use some combinations of the mentioned strategies.

The first examined group is relevant to the application area of the upper limb rehabilitation mechanism in assistive machines, motion amplifiers, and haptic uses. They can be furthermore classified depending on their utilization on human body: hand, forearm, and full limb or joined section of rehabilitation mechanism. Power transmission tabulation depends on the method used: gear, cable, Geneva mechanisms, belt drive, ball screw drive, hybrid transmission, and so on. As rehabilitation machines cooperate with human patients, it is crucial to study the whole system as a coupled mechanical scheme. The main goal of exoskeleton robot controllers is to control the robot focusing on human movement intents. ${ }^{21}$ The mode of operation of rehabilitation machines can be categorized by the input information received by controller, controller architecture, and controller output. ${ }^{33}$ Based on input data to the regulator, the procedures can be additionally characterized as patient signal-based controller, no human-based control methods, and structure autonomous approaches. The signal classification is fundamental in the identification of the human motions. Surface electromyography (hereafter sEMG) signals have long been used in prosthetic control; in the past few years, they were used to control robots dedicated to the rehabilitation of human limbs. In some rehabilitation prototypes, ${ }^{13,34}$ sEMG signals have been used with success. In Hasegawa and Oura, ${ }^{15}$ the brachii model sEMG-based control technique is used to guide a 4-DOF robot, being the same adjustable for the majority of patients. Furthermost sEMG based procedures has binary nature. ${ }^{34}$ In order to improve the characteristics of the regulator schemes for exoskeleton robots, diverse control approaches are found in various exoskeleton developments. ${ }^{35-38}$ In 2008, an assistance control method was proposed by Wolbrecht et al., ${ }^{36}$ based on robot-aided movement to be adopted after strokes. Among all the needed characteristics, the following are desired: high mechanical conformity, the capacity in assisting patients in the required movements, and the aptitude in proving only the essential assistance. The assistance as-needed is obtained by introducing a new reducing term force to the controller that decreases the output force from the robot in the presence of small task errors. A novel AAS paradigm (hereafter assistance-as-needed) using formulations to evaluate the necessary support for the patient is proposed by
Carmichael. ${ }^{39}$ The method proposed by Ugurlu et al. ${ }^{35}$ relies on an accurate identification and compensation of the joint perturbation forces produced by viscous friction and gravitational effects. The force/sensorless power assist regulator introduced by $\mathrm{S}$ Oh et al. ${ }^{38}$ uses only encoders to obtain the necessary force data and to return power regulator performances. In the control approach focused on admittance, the force applied by the patient is measured and the movement is the consequence. Impedance-admittance have balancing pros and cons. ${ }^{40}$ Robots equipped with control based on impedance have stable interaction and lower precision in the workspace, due to friction phenomena. A way to improve the precision is represented by the use of torque sensors' loop and low-friction linkages. Impedance regulator approach has been instigated in MIT

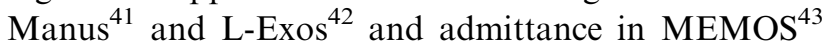
and iPAM $^{44}$ In this work, the robotic rehabilitation system implements the force-based control to recuperate the adequate muscle tone of the disease limb. The amplitude of EMG signals is used as a function of the force applied by the patient.

This article presents a methodology for elbow functional recovery based on the use of sEMG signals as input to manage a single-DOF robot arm. Active assisting and resisting force controls were implemented. The correlation analysis between sEMG signal and force exerted by the subject was studied in opening and closing tests with the purpose of validating the methodology. sEMG-driven control is demonstrated by experimental tests on healthy subjects that confirm the proposed architecture. Finally, a control scheme is proposed relying on the comparison between a reference sEMG signal measured on the healthy arm and on the impaired arm.

\section{Robotics device and movement characterization}

The robotic device (Figure 1) is a conventional exoskeleton ${ }^{12}$ that can be divided into two fundamental subassemblies: the elbow subsystem and the wrist part. The first part consists of two vertical supports fixed to a frame, directly connected to a direct drive torque motor. The subject is seated in front of the robotic system, as shown in Figure 2(a). The wrist assembly has a semi-circular structure that rotates around its $\mathrm{Y}_{3}$-axis (Figure 2(b)). The flexion and extension of the elbow, as presented in Figure 2(c), are achieved due to direct drive motor connected with a customized belt.

The minimization of the inertia connected to the patient ensures the security features and is the goal of the configuration presented in this article. A mechanical emergency stop mechanism has been created with the aim of assurance margins of flexion/extension 


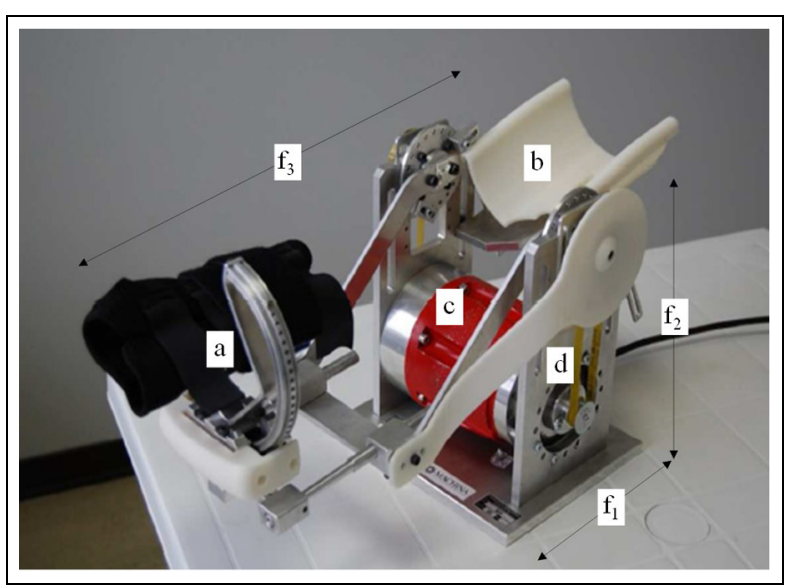

Figure I. Prototype of the SDOF rehabilitation robot arm.

(hereafter F-E) and pronation/supination (hereafter P-S) motions.

Furthermore, in the event that the wrist is P-S, the device is fitted with a torque restricting device. In this way, it is possible to adapt the elbow's F-E transmission, so that active or passive movement mode can be performed. Ergonomic criteria permitted to develop the suggested design coherently with the anthropometric parameters of upper limb. The customization of the diverse articular dimensions concerns the following six linear movements and one rotation of the wrist support.
Three referred to the motion: vertical change in the axis of pronation-supination, wrist movement support to avoid a compression of the arm, and transverse movement of the wrist support to accommodate the lateral displacement of the hand during F-E and P-S. Three related to the human-device dimensions: arm length adjustment, axis adjustment of the drive pulley assembly belt, and adjustable positioning arm. The rehabilitation robot consists of three main assemblies: (1) the patient's forearm, (2) the elbow junction mechanism, and (3) the assembly for the wrist P-S. Table 2 lists all the parameters and they are explained in Figure 3. The blue line in this figure is a schematic representation of the connection between the upper arm (2) and the wrist support (3).

The angles $\alpha_{2}$ and $\alpha_{3}$ are identified from the preliminary tunings based on the size of patient's upper limb. Considering $\Delta \mathrm{x}$ as the rehabilitation length adjustment, necessary for patient customization, the relations defining the parameters $\mathrm{L}, \alpha_{2}$, and $\alpha_{3}$ can be expressed as

$$
\begin{gathered}
\mathrm{L}=\mathrm{L}_{\max }-\Delta \mathrm{x} \\
\alpha_{2}=\arctan \left(\frac{\mathrm{YG}_{2}}{\mathrm{XG}_{2}}\right) \\
\alpha_{3}=\arctan \left(\frac{\mathrm{YG}_{3}}{\mathrm{~L}-\mathrm{XG}_{3}}\right)
\end{gathered}
$$

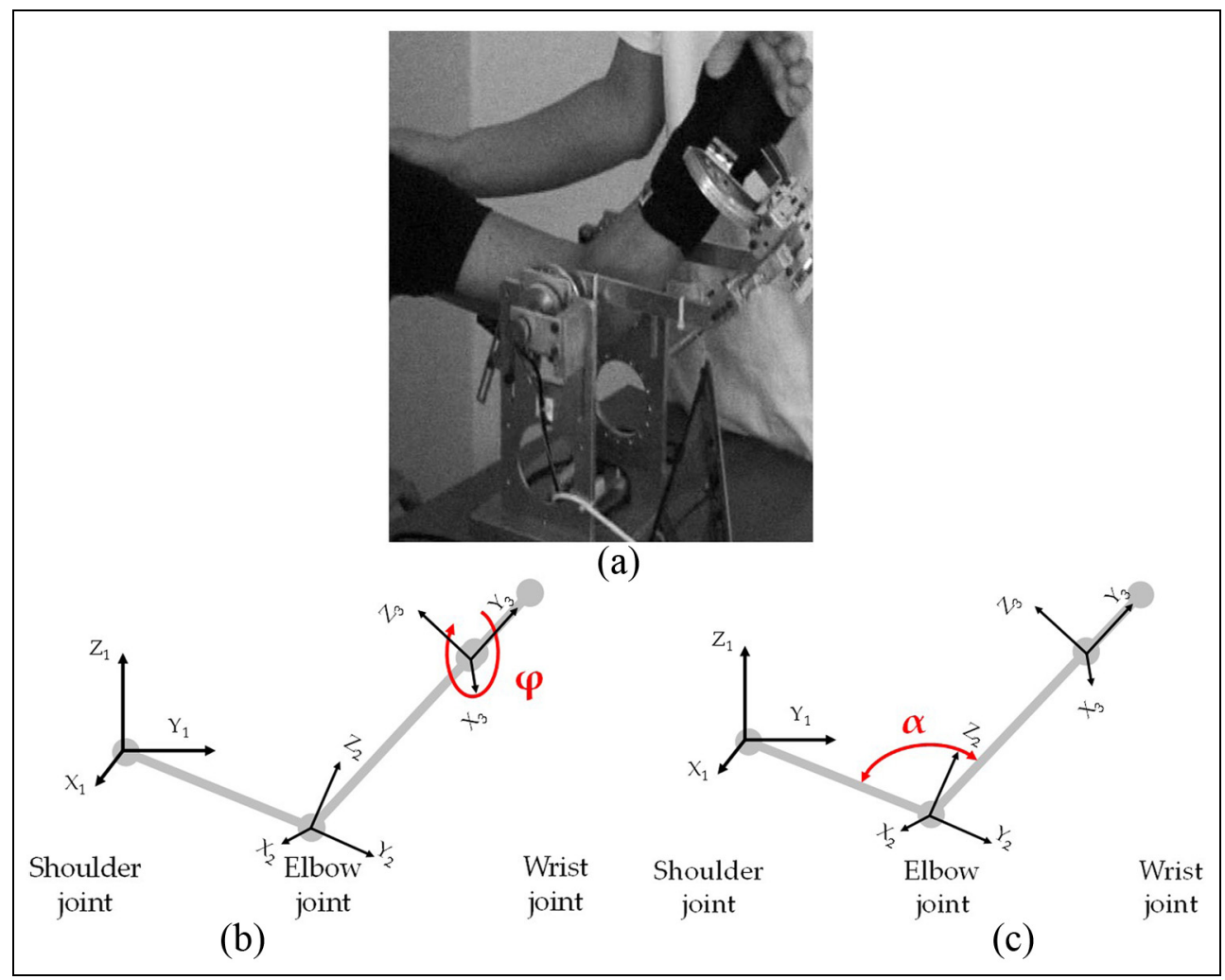

Figure 2. (a) Human-machine physical interaction and (b) wrist and (c) elbow movement description. 
Table 2. Summary of human-mechanism parameters.

\begin{tabular}{|c|c|}
\hline Nomenclature & Description \\
\hline $\mathrm{L}$ & $\begin{array}{l}\text { Distance between elbow and the wrist of } \\
\text { patient }\end{array}$ \\
\hline$I_{I}$ & $\begin{array}{l}\text { Distance between CG of patient's forearm } \\
\text { and Z2-axis }\end{array}$ \\
\hline $\mathrm{I}_{2}$ & Distance between CG2 and Z2-axis \\
\hline $\mathrm{I}_{3}$ & Distance between CG3 and Z2-axis \\
\hline$\alpha$ & Angle of elbow flexion \\
\hline$\alpha_{2}$ & $\begin{array}{l}\text { Angle between } Y 2 \text {-axis of the forearm and } \\
\text { CG2 }\end{array}$ \\
\hline$\alpha_{3}$ & $\begin{array}{l}\text { Angle between the longitudinal axis of the } \\
\text { forearm and CG3 }\end{array}$ \\
\hline $\mathrm{L}_{\max }$ & $\begin{array}{l}\text { Maximum length of the device that is able to } \\
\text { support }\end{array}$ \\
\hline $\mathrm{F}_{\mathrm{i}}$ & Inertial forces of mechanical components "i” \\
\hline$\tau_{\mathrm{i}}$ & Torques of mechanical components \\
\hline & Mass of patient's forearm \\
\hline$M_{2}, M_{3}$ & $\begin{array}{l}\text { Mass of mechanical subassembly } 2 \text { (blue), and } \\
\text { subassembly } 3 \text { (red) }\end{array}$ \\
\hline
\end{tabular}

CG: center of gravity.

The estimation of $F_{\text {therapist }}$, the force specified by therapist, and the related resistant torque for the movement are obtained by carrying out the rotation around the elbow's cylindrical hinges, as equation (4)

$$
\begin{aligned}
& \mathrm{F}_{\text {therapist }} \cdot \mathrm{L}=\mathrm{M}_{1} \cdot \mathrm{g} \cdot \mathrm{l}_{1} \cdot \cos \alpha+\mathrm{M}_{3} \cdot \mathrm{g} \cdot \mathrm{l}_{3} \cdot \\
& \cos \left(\alpha-\alpha_{3}\right)+\mathrm{M}_{2} \cdot \mathrm{g} \cdot \mathrm{l}_{2} \cdot \cos \left(\alpha-\alpha_{2}\right) \\
& +\sum_{\mathrm{i}, 2,3} \mathrm{~F} \cdot \mathrm{L}+\sum_{\mathrm{i}, 2,3} \tau
\end{aligned}
$$

Throughout the rehabilitation phase, functional motion capacities need to be properly measured. ${ }^{45,46}$ The information can give details regarding patients' disability level and the efficacy of current rehabilitation therapy. The range of motion (ROM) and the resistant torque of patient are parameters connected to the upper limb rehabilitation and are of utmost importance. The rehabilitation robotics device can be optimized with regard to actuation sizing and motion planning. This process covers the estimation of the ROM of the movements and of the force created by a therapist. The development of a dedicated measuring system has permitted to analyze the movements carried out by the physiotherapist during the treatment of diverse pathologies. The ROM of the flexion-extension and pronation-supination is estimated through a rotational potentiometer, the force exerted by the therapist through a uniaxial load cell. Once the force created by the physiotherapist was measured, the resistive torque of the elbow can be estimated through the dynamical equilibrium at the rotation around the elbow's cylindrical hinges. The measurement of this torque is highly significant, as it leads to an index of resistive torque created by elbow during flexion. The results are summarized in Table 3.

\section{Control strategies and active sEMG force- based control}

Recovering patient's muscle-articular functionality and providing him or her an autonomous ability to control his or her movement is the objective of robotics rehabilitation. For this reason, the control system must be as flexible as possible, so that it can be widely reconfigured and used for different patients. Opportune control algorithms have been developed in order to realize a movement, adapted for many kinds of upper limb diseases. Table 4 describes the different types of rehabilitation in terms of features and definitions that were implemented in the considered rehabilitation device. Similar control strategies were implemented in a previous work in a device for hand rehabilitation. ${ }^{46,48-}$ 50

The rehabilitation therapy needs a periodical assessment in order to verify the effectiveness of exercises on muscular functionalities and must be continuously adapted to the actual patient performances. sEMG signal can be a useful indicator of the patient's muscle conditions and can be used in the robotic device control. Preliminary experimental tests were conducted to validate the sEMG force-based methodology. The correlation between the sEMG signal and the force exerted during the grasping and the lifting of an object was verified. The positive results of these tests, reported in section "Methodology validation for sEMG signals' use," encouraged the pursuit of research. An active sEMGbased force control could be implemented in a more innovative mode, as reported in Figure 4. This kind of control is based on the comparison between the initial patient assessment and the actual one. In a preliminary phase, some tests on the subject allow to collect a database of the root mean square (RMS)/sEMG signals related to the initial condition of the patient. During

Table 3. Range of movement of elbow and forearm.

\begin{tabular}{llll}
\hline Types of motions & Anatomical range & Proposed device $($ min; nominal; max $)$ & Resistant torque, N m (female)/(male) \\
\hline Flexion & $140^{\circ}-145^{\circ}$ & $\left(115^{\circ} ; 120^{\circ} ; 140^{\circ}\right)$ & $(0 ; 0.41) /(0 ; 0.52)$ \\
Extension & $0^{\circ}-15^{\circ}$ & $0^{\circ}$ & \\
Pronation & $80^{\circ}-90^{\circ}$ & $\left(-80^{\circ} ;-88^{\circ} ;-90^{\circ}\right)$ & $(0 ; 0.07) /(0 ; 0.16)$ \\
Supination & $80^{\circ}-90^{\circ}$ & $\left(80^{\circ} ; 88^{\circ} ; 90^{\circ}\right)$ & \\
\hline
\end{tabular}


Table 4. Control strategies of rehabilitation implemented for the robotics device.

\begin{tabular}{lll}
\hline Rehabilitation & Characteristic & Description \\
\hline $\begin{array}{l}\text { Continuous } \\
\text { passive }\end{array}$ & $\begin{array}{l}\text { Movement with } \\
\text { predefined trajectory } \\
\text { Movement with speed } \\
\text { control }\end{array}$ & $\begin{array}{l}\text { The patient follows a predetermined pathway established by physiotherapists. } \\
\text { In the absence of any defined trajectory, only the start and end points of a } \\
\text { therapy are set out. The movement is obtained through the adjustment of the } \\
\text { rotational speed of the motor. Being the machine homo-kinetic, imposing the } \\
\text { speed permits to immediately monitor the device's behavior. During the } \\
\text { movement a proper logic of motion will modulate the speed based on the } \\
\text { responses of the patients. } \\
\text { Open-loop control of the force: the motor applies a specific torque (resistive } \\
\text { or assistive) to the patient's arm in response to difference between the RMS } \\
\text { values of sEMG signals of the healthy and the impaired arms. }\end{array}$ \\
\hline SEMG force-based & control &
\end{tabular}

sEMG: surface electromyography; RMS: root mean square.

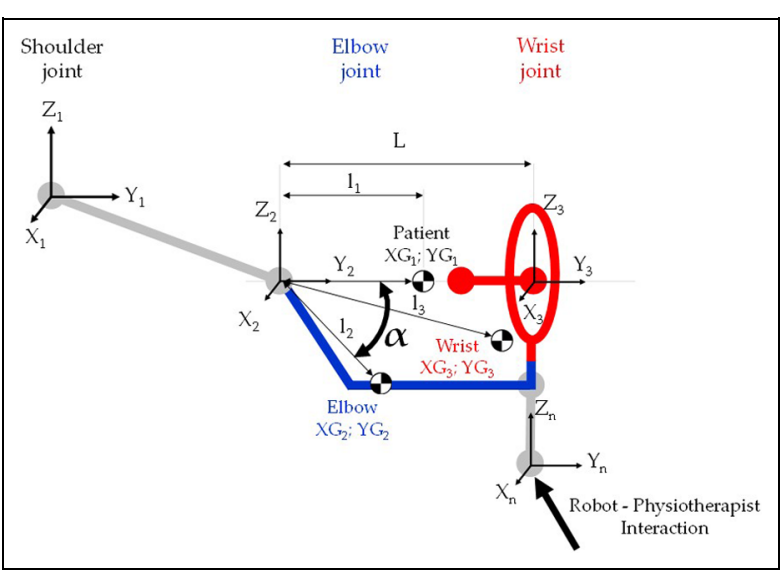

Figure 3. Mechanism scheme and reference layout including all human-mechanism parameters.

rehabilitation sessions, the assisting or resisting forces are adjusted. The control system adapts the force exerted by the robotic device comparing the current RMS/sEMG signals with the initial one.

Considering a stroke patient affected by hemiplegia, the sEMG force-based control measures the sEMG signals of flexion and extension of both healthy and impaired arms and uses them to extract proportional features of the forces, $F_{\text {healthy }}$ and $F_{\text {impaired. The control }}$ unit generates opportune commands so that the torque motor's driver furnishes to the actuator a force related to the difference between these two forces. $F_{\text {healthy }}$ is measured at the beginning of the therapy session while the $F_{\text {impaired }}$ is continuously monitored during rehabilitation, so that the system adjusts itself in an active mode.

\section{Methodology validation for sEMG signals' use}

The correlation analysis between sEMG signal and force exerted by the subject was performed in opening and closing tests. The sequence considers gripping phase of a preloaded under pressure plastic bin and the measure of the pressure during the gripping period. sEMG signals are measured with a bipolar methodology. In Figure 5(a), the electrodes' positioning for the tests is shown: two electrodes on the extensor digitorum and the extensor carpi radialis, two on the palmaris longus and the flexor carpi ulnaris, and a reference electrode on the wrist. The principal components

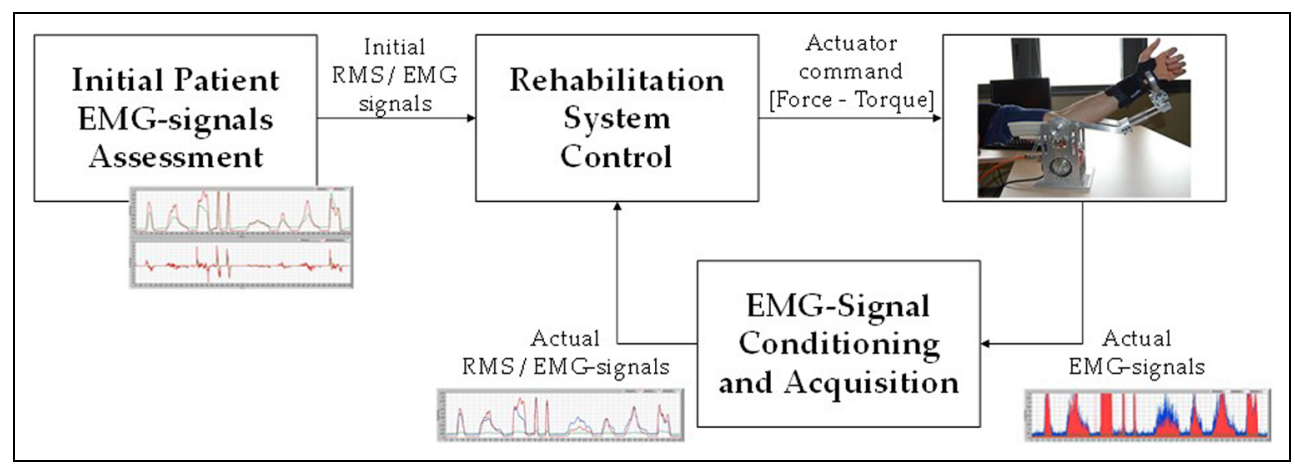

Figure 4. sEMG force-based control scheme. 


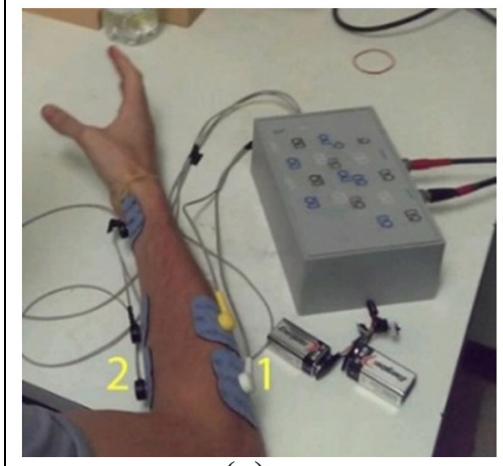

(a)

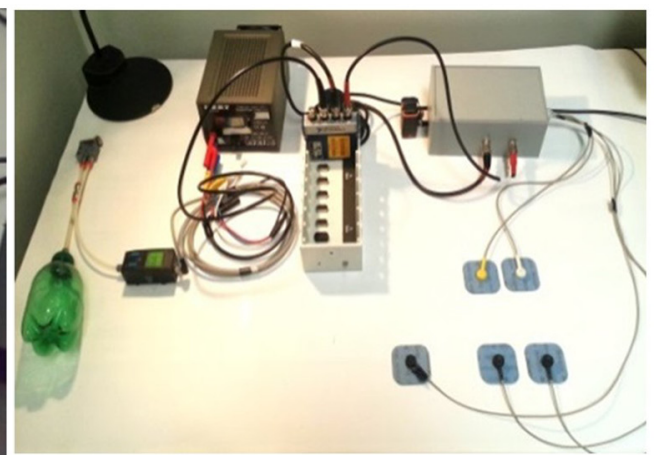

(b)
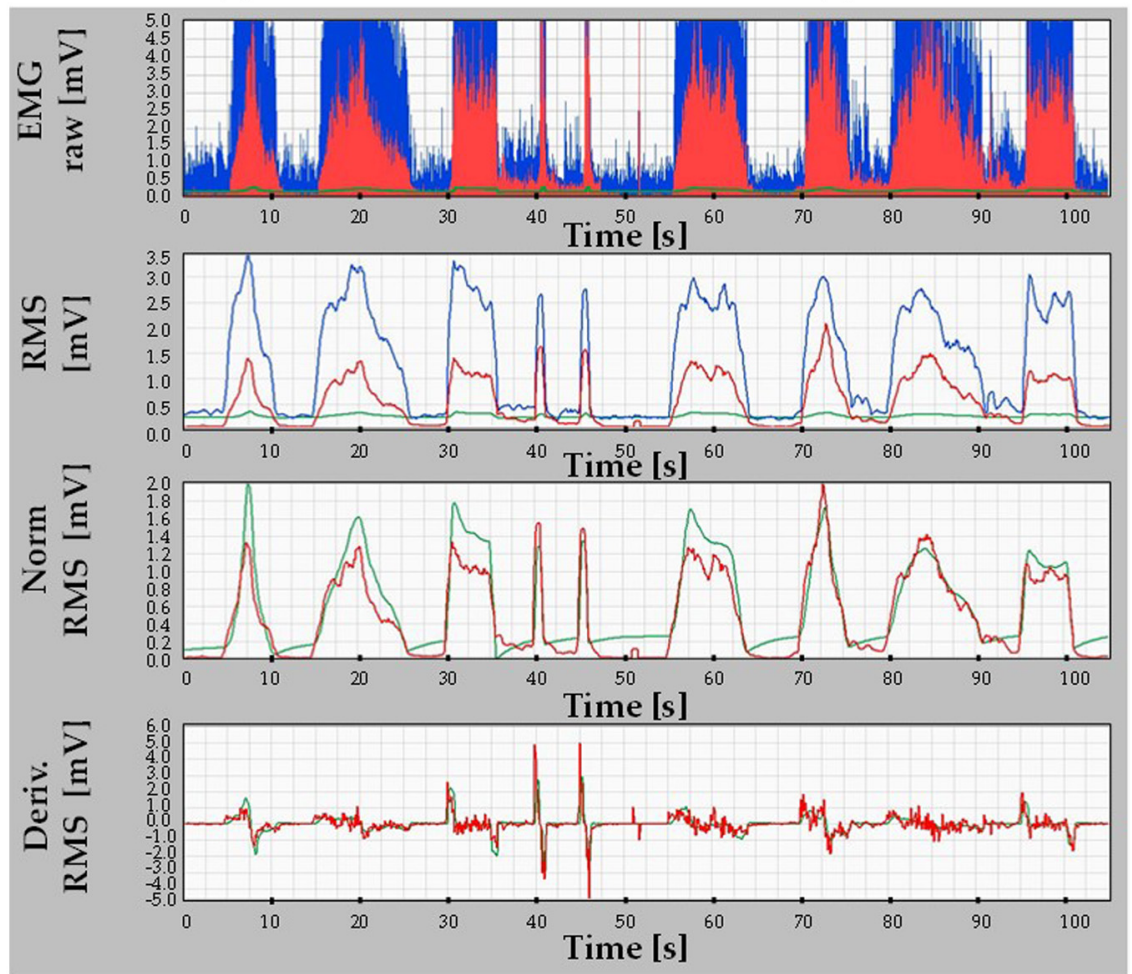

(c)

Figure 5. (a) Measure of patient's arm, (b) test bench, and (c) SW interface.

needed during the tests (Figure 5(b)) were a plastic bin, a pneumatic valve, an electro-pneumatic pressure transducer, a power supply, an acquisition board, electrodes, and a personal computer. The software interface used to acquire and to process the signals is illustrated in Figure 5(c).

Figure 6 shows the test protocol carried out in the Cartesian plane, where the time is represented along the $x$-axis and the ratio between the actual closing and the maximum force along the $y$-axis.

The healthy subjects were involved to perform tests with a sequence of opening and closing. Every subject performed tests 10 times. Every test lasted $105 \mathrm{~s}$ in total, and a rest time was selected between every movement in order to get an accurate signal. Figure 7 illustrates sEMG flexion (red), sEMG extension (blue), and pressure (green) signal trends (a) and the relative RMS values of the signals (b), acquired on a patient in single test for representation.

Pressure and sEMG signals are normalized so that they can be compared, and the normalized RMS values are presented in Figure 8. Normalization uses gains to obtain a final waveform in range from 0.0 to $2.0 \mathrm{mV}$. The sEMG and closure pressure signals are correlated. In addition, Figure 8 highlights the pressure decreases and the sEMG flexion signal while rehabilitation task takes place. The maximum force was reached but due to the physical limits of the patient, it was not able to 


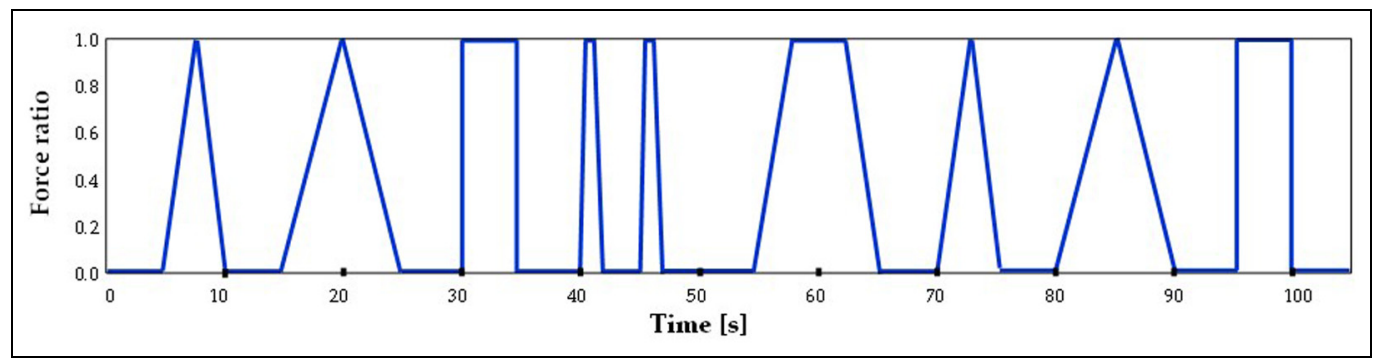

Figure 6. Test protocol composed by a sequence of opening and closing movements.

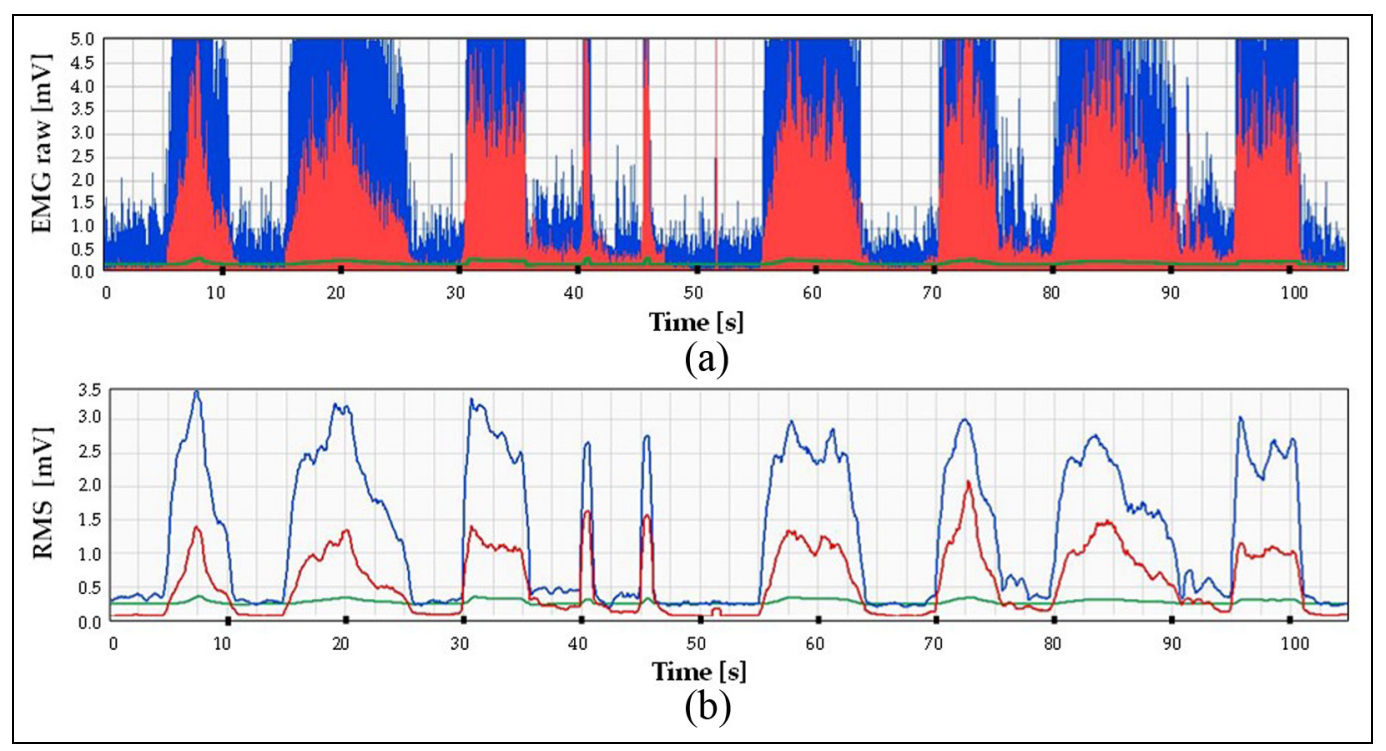

Figure 7. (a) sEMG and pressure signal trends—sEMG flexion (red line, peak $4.2 \mathrm{mV}$ ), sEMG extension (blue line, peak $7.4 \mathrm{mV}$ ), and pressure (green line, peak $0.35 \mathrm{mV}$ ) signal and (b) RMS values of the signals—sEMG flexion (red line, peak 2.I mV), sEMG extension (blue line, peak $3.9 \mathrm{mV}$ ), and pressure (green line, peak $0.23 \mathrm{mV}$ ) signal.

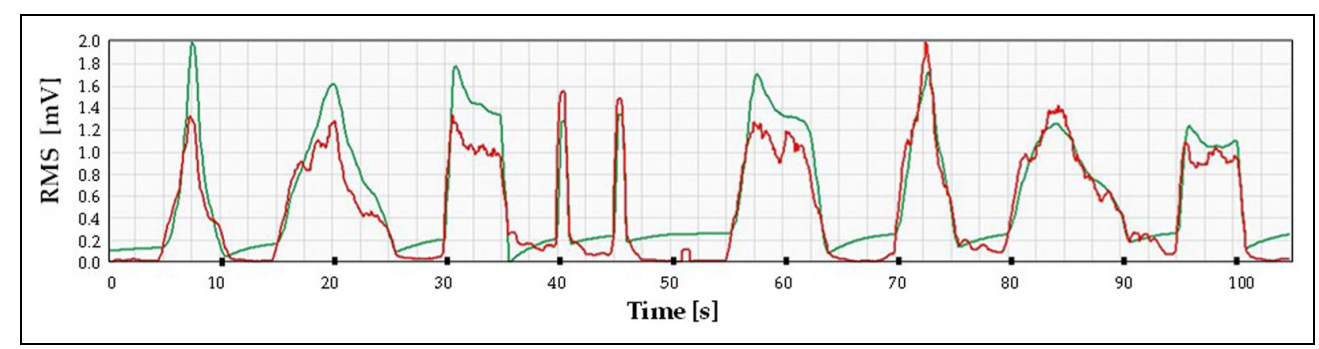

Figure 8. RMS of the flexion EMG signal (red) and normalized pressure signal (green).

resist in a state of maximum contraction for a time of $5 \mathrm{~s}$. The pressure signal and sEMG signal, in quadrature waveforms and pulses, present the increase in tension at the muscle level.

\section{sEMG force-based control experimental validation}

Continuous passive and active sEMG-based controls are two of the diverse possible control strategies the system can handle. As far as the EMG-based control is concerned, the authors concentrated their studies on the biceps brachii and the triceps brachii muscles, characterizing both the flexion and extension movements. The sEMG signals of the muscles are measured with an electrode's bipolar configuration. During the evaluation of the contraction level of the biceps and triceps muscles, five electrodes were used, as shown in Figure 9.

Rather than operating on two dissimilar reference electrodes (one for each muscle), just one will be placed 


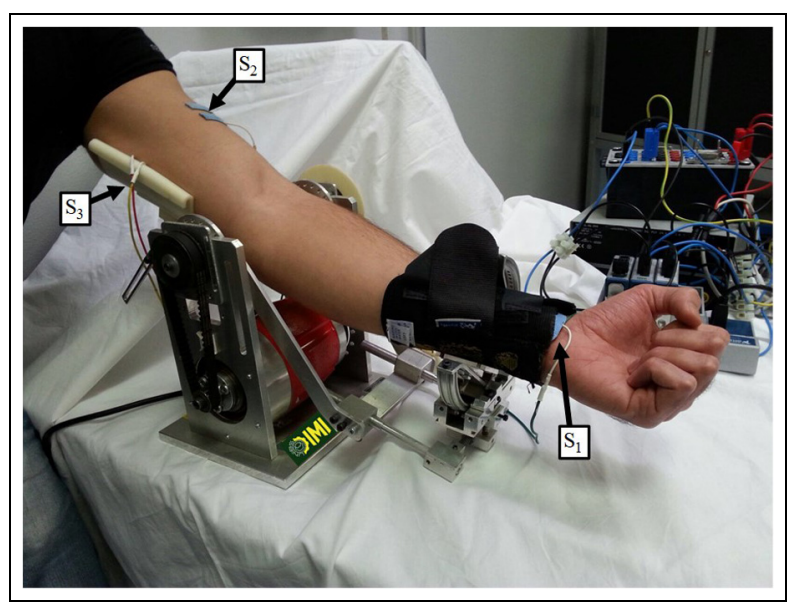

Figure 9. sEMG electrodes' configuration for elbow rehabilitation.

at the wrist. A preliminary experimental test campaign has been carried out for the sEMG force-based control, considering a triggered ON-OFF control and a proportional control, both, respectively, in resistant and assistive modes. The control variable is obtained as in equation (5)

$$
\begin{aligned}
\mathrm{EMG}_{\mathrm{RMS}}= & \mathrm{EMG}_{\mathrm{RMS}}(\text { triceps brachii) } \\
& -\mathrm{EMG}_{\mathrm{RMS}}(\text { biceps brachii })
\end{aligned}
$$

As regards the ON-OFF control, the activation of the motor with a prefixed torque value takes place once the controlling variable exceeds a threshold. The considered thresholds are positive and negative; hereafter, $\mathrm{k}_{+ \text {on/off }}$ and $\mathrm{k}_{- \text {on/off }}$. Considering that the motor normally moves in the positive and negative directions, it has been chosen to tune two thresholds depending on the patient. The threshold values are evaluated through a specific calibration procedure, by comparing the sEMG $\mathrm{RMS}_{\mathrm{R}}$ mean value measured on the healthy arm and the correspondent on the impaired arm. The proposed control allows both the active assisting and active resisting therapies. Figure 10(a) shows well the assisting mode; once the threshold is exceeded, the motor performs a torque value. The torque was estimated by comparing the $s E M G_{R M S}$ signal measured on the impaired arm and the value measured in the calibration phase on the healthy arm. In this situation, the torque produced follows every time the direction of the movement (Figure 10(b)).

The ON-OFF control was also studied in resistive mode. The main outcome is summarized in Figure 11(a) that illustrates sEMG signals. When the threshold is exceeded, the motor performs a torque in the opposite motion direction (Figure 11(b)) and the constraintinduced therapy can be respected. In order to minimize the safety risk for the patient due to robot dynamics, the task performed in the considered time period was reduced by $45 \%$. Five complete rehabilitation movements are performed in $80.0 \mathrm{~s}$. The preliminary campaign confirms that sEMG principle is satisfactory; in that way, it is possible to progress the rehabilitation exercise for the under evaluation disease. The muscles' activation level is specified by the resultant RMS, and for this reason it could be considered as an indicator of the patient's force intensity in the proportional control. This aspect drives the rehabilitation protocol in which

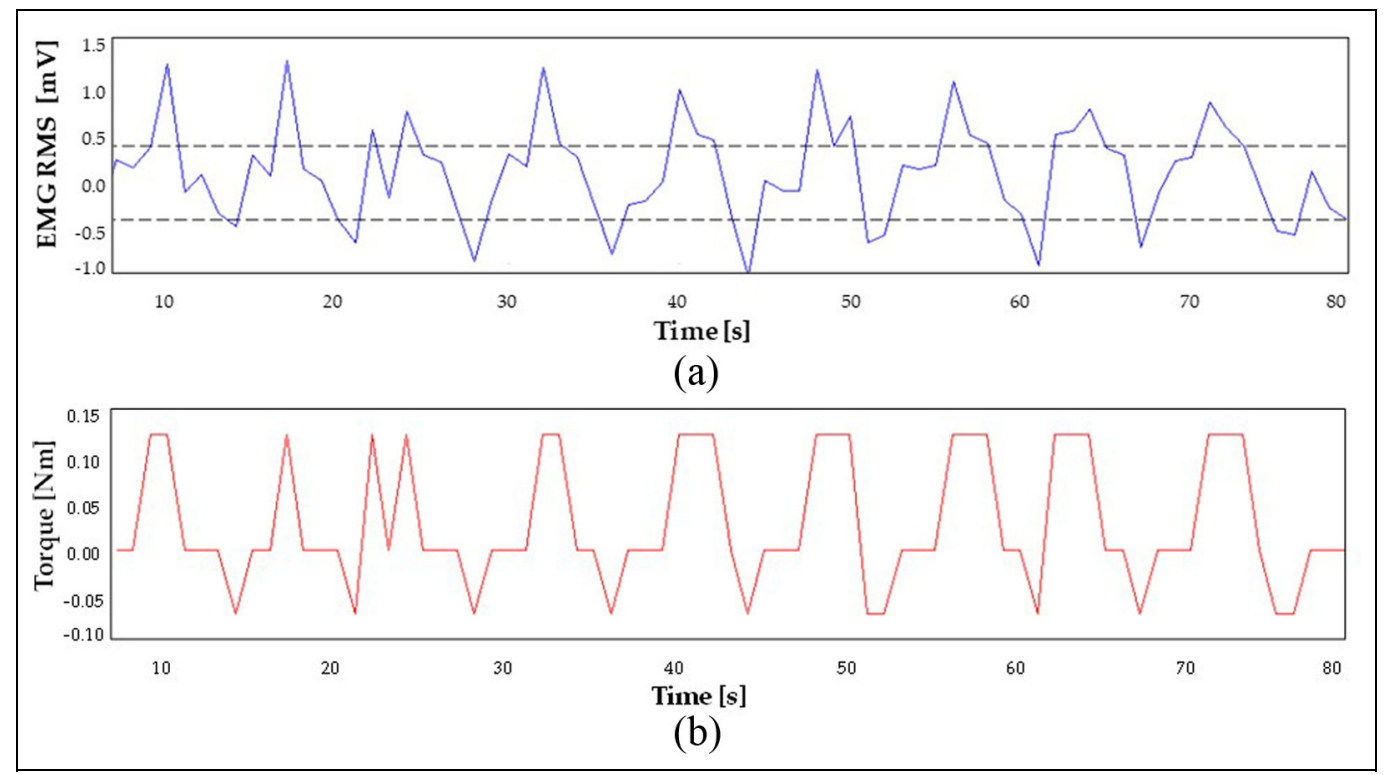

Figure 10. sEMG force-based control: ON-OFF and assisting mode: (a) sEMG $\mathrm{RMS}_{\mathrm{S}}$ signal $(\mathrm{mV})$ for a predetermined rehabilitation task and (b) torque produced during the executed movement $(\mathrm{N} \mathrm{m})$. 


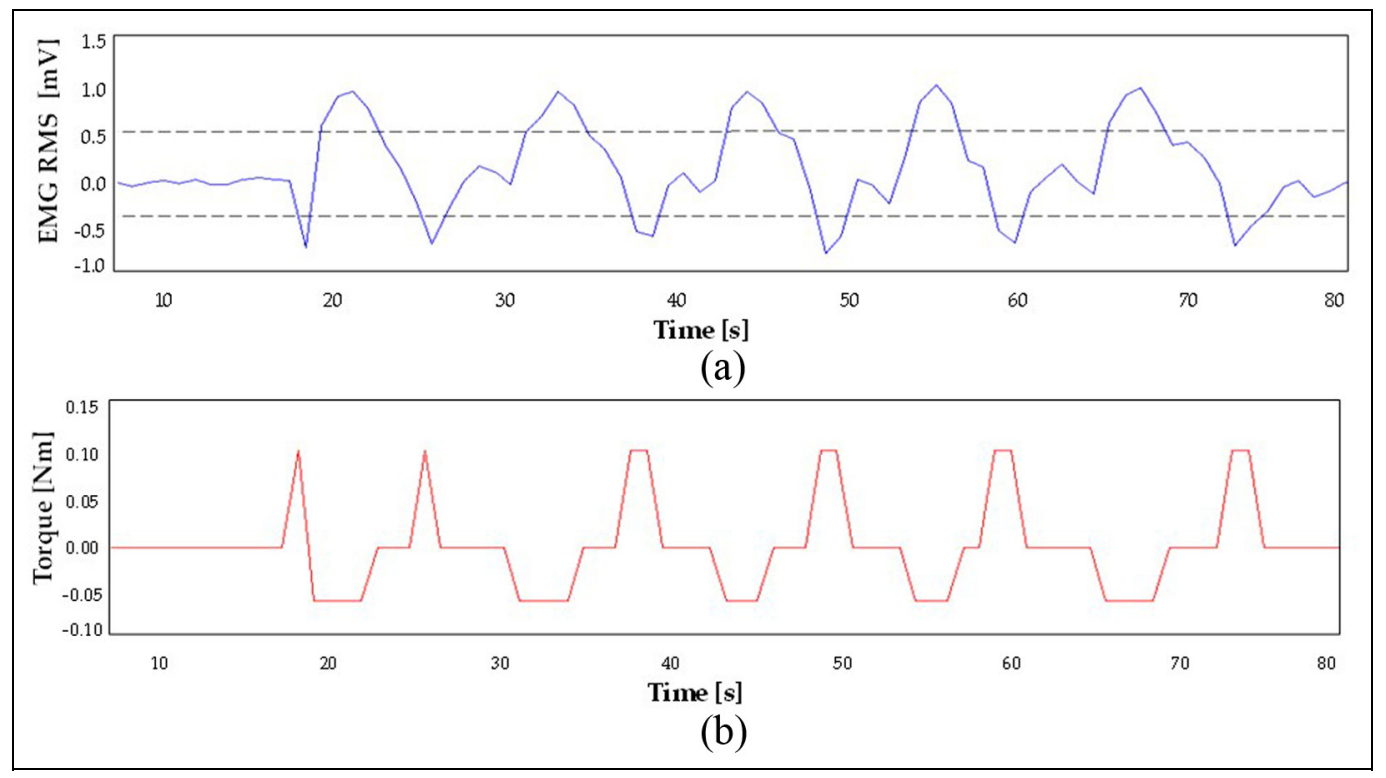

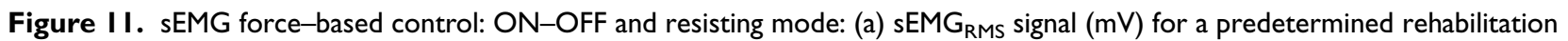
task and (b) torque during the executed movement in the opposite motion direction $(\mathrm{N} \mathrm{m})$.

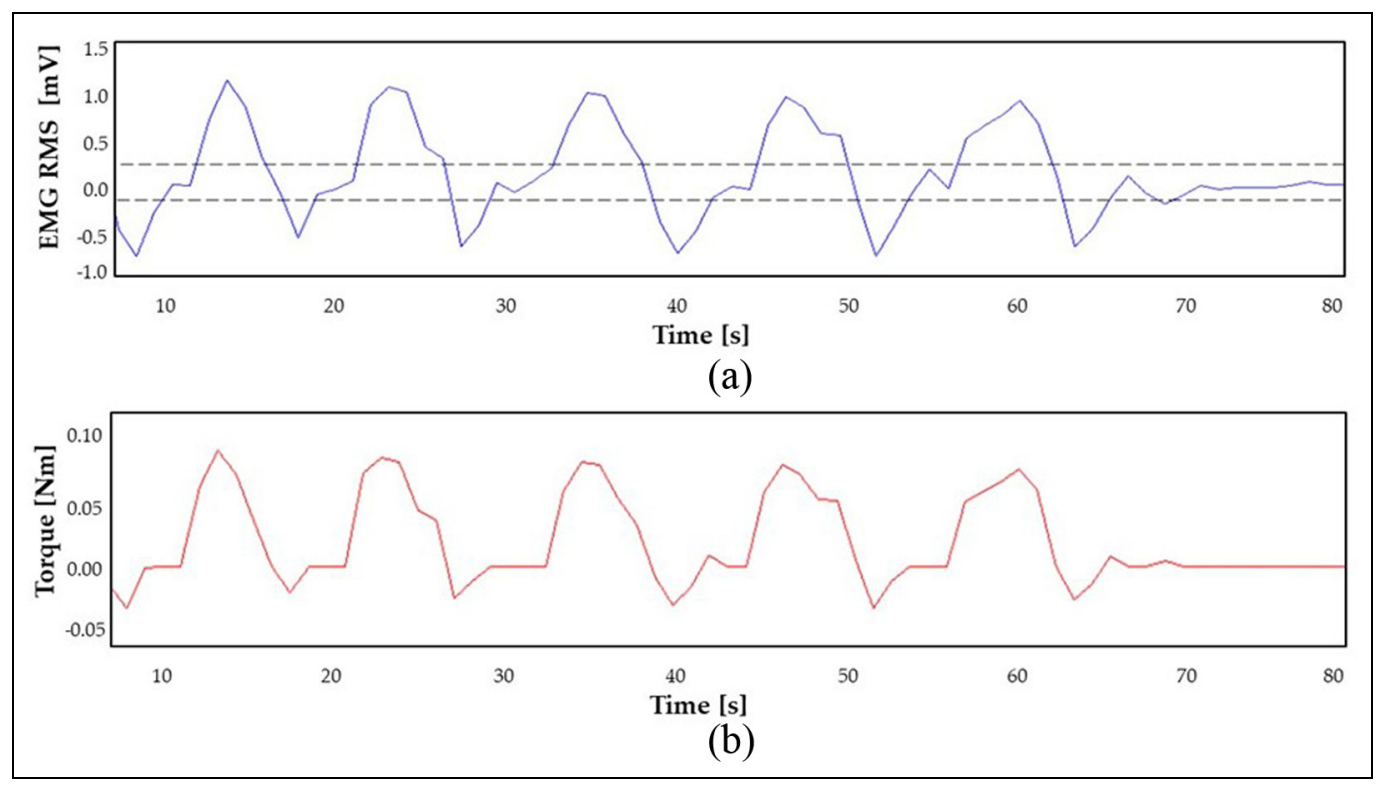

Figure I 2. sEMG force-based control: proportional and assisting mode: (a) sEMGRMS signal (mV) for a predetermined rehabilitation task and (b) torque produced during the executed movement $(\mathrm{N} \mathrm{m})$.

the measured signals need to be converted to a key performance indicator of the efficacy of rehabilitation therapy.

This control technique has the aim to perform a movement proportional to the force applied by the subject; the higher the patient's force, the higher the torque. Figures 12 and 13 confirm the proportional control results. The assisting mode is illustrated in Figure 12(a). During this process, the torque produced by the motor is proportional to the sEMG-RMS. In this case, as the torque obtained is always in the direction of the movement (Figure 13(b)), it helps the patient to move his or her arm. In this way, thresholds are needed to make sure the motor does not produce a torque every time the resultant is small or in the presence of noises by setting $\mathrm{k}_{\text {prop }}$ equal to 600 .

Figure 13 shows the resisting mode, in which the motor produces an opposite proportional torque to the sEMG resultant RMS (Figure 13(a)). Therefore, the torque produced by the motor (Figure 13(b)) is 


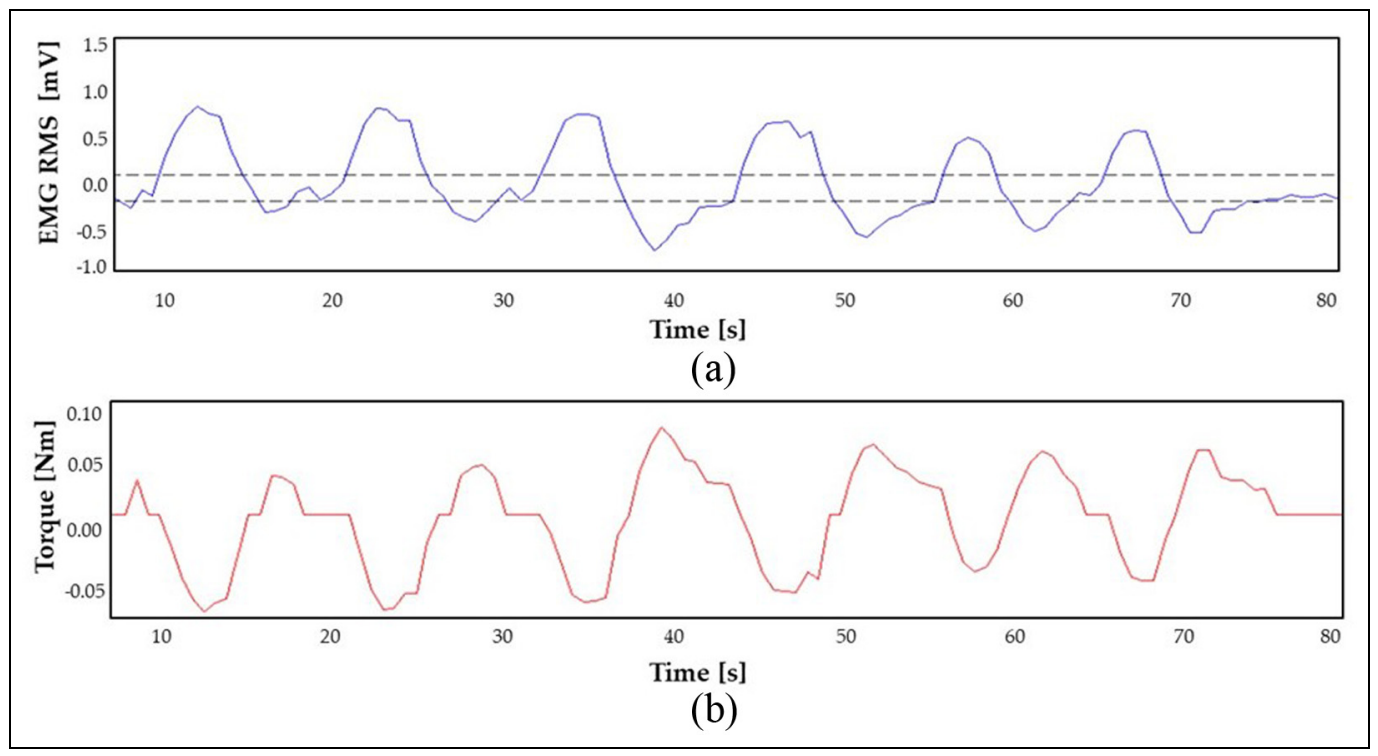

Figure I3. sEMG force-based control: proportional and resisting mode: (a) sEMG $\mathrm{RMS}_{\mathrm{S}}$ signal (mV) for a predetermined rehabilitation task and (b) torque during the executed movement in the opposite motion direction $(\mathrm{N} \mathrm{m})$.

opposed to the arm moving direction, thus performing a constraint-induced therapy, with $\mathrm{k}_{\text {prop }}$ close to 500 .

The main limitation encountered while using the sEMG control is due to the noise as perturbation factor. The commanding signal is influenced by the environmental noises (electromagnetic source) of the other devices and by the crosstalk effect. The second constraint is the muscles' variability that directly influences the rehabilitation system calibration in terms of thresholds, $\mathrm{k}^{+}$on/off, $\mathrm{k}^{-}$on/off, $\mathrm{k}_{\text {prop. }}$. The authors have developed further experimental campaigns with the aim of comparing sEMG-based control with a force-based one, in which the force feedback is given by a load cell sensor. A load cell Interface SM 100, with $3 \mathrm{mV} / \mathrm{V}$ FS sensibility and a measuring range $(0-100 \mathrm{~N})$, was used and installed on the wrist support, as shown in Figure 14. The data acquisition process used for load cell control is similar to the EMG control except that no filtering and no RMS calculation are executed on the raw signals.

As for the EMG-based control, ON-OFF and proportional controls were implemented in both the modalities, resistant and assistive. The generation of the command to the actuator follows the same logic described in section "sEMG force-based control experimental validation" for the sEMG force control; the main difference is in the choice of the thresholds. In this case, having only the signal measured on the diseased arm, the thresholds are fixed on the basis of the force measured by the load cell. No comparison with the healthy arm is possible during active rehabilitation.

The load cell testing campaign highlighted similar outputs in terms of control results in comparison with

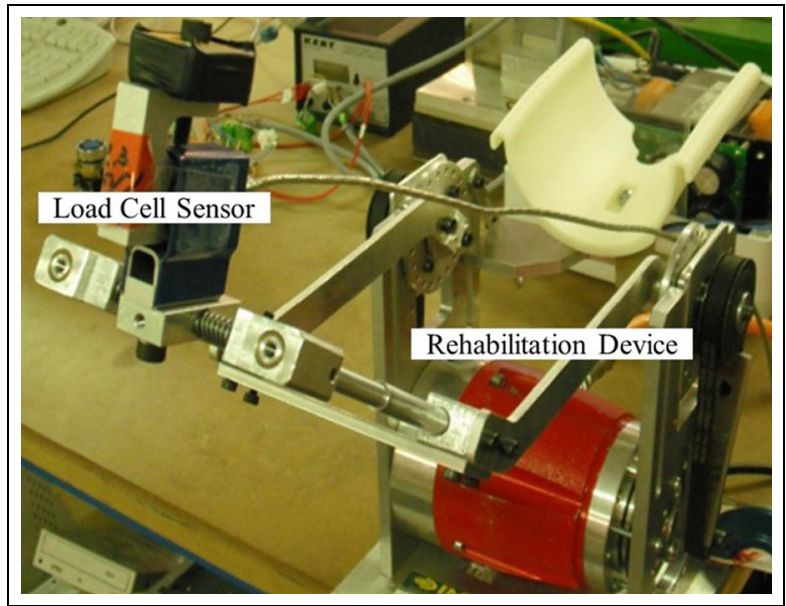

Figure 14. Robotic rehabilitation device with load cell sensor feedback.

sEMG-based one, but it has also showed some negative aspects:

- Measuring equipment was expensive and it was bulky in the area of the wrist support.

- System does not highlight the same compactness compared to sEMG configuration.

- Load configuration does not allow the real-time reference with healthy limb in patient with hemiplegia disease.

For these reasons, the sEMG approach appears to be a more effective solution for elbow rehabilitation. 


\section{Conclusion and future developments}

The recovery treatment device seems to produce a successful result according to the initial experimental campaign of validation. A robotic exoskeleton matching the elbow-forearm has been advanced to grant a valid rehabilitation therapy for persons with physical disabilities of upper limb motion. The sEMG force-based control permitted to implement adequately both the on/off control and the proportional control. As far as the next developments of the activity are concerned, first, using in the best possible way the sEMG force-based control on an efficient campaign of experimental tests on patients with dissimilar disabled status. Second, developing activity games linked to the device, so that the patient is motivated to the rehabilitation. Then, granting to the patients feedbacks regarding the progress of the rehabilitation program or visual/audio feedback of ongoing exercises. Finally, for the device used at home, creating an Internet-based connection of the system to opportune applications, in a way that the rehabilitation results can be remotely monitored by the physiotherapist, who then decides the therapy to follow.

\section{Declaration of conflicting interests}

The author(s) declared no potential conflicts of interest with respect to the research, authorship, and/or publication of this article.

\section{Funding}

The author(s) received no financial support for the research, authorship, and/or publication of this article.

\section{ORCID iD}

Alberto Borboni iD https://orcid.org/0000-0001-7069-1095 Nicola Pellegrini iD https://orcid.org/0000-0002-6108-3941

\section{References}

1. Stienen AHA, McPherson JG, Schouten AC, et al. The ACT-4D: a novel rehabilitation robot for the quantification of upper limb motor impairments following brain injury. In: Proceedings of the IEEE international conference on rehabilitation robotics, Zurich, 29 June-1 July 2011, pp.1-6. New York: IEEE.

2. Hogan N, Krebs HI, Charnnarong J, et al. MITMANUS: a workstation for manual therapy and training. I. In: Proceedings of the IEEE international workshop on robot and human communication, Tokyo, Japan, 12 June 1992, pp.161-165. New York: IEEE.

3. Krebs HI, Palazzolo JJ, Dipietro L, et al. Rehabilitation robotics: performance-based progressive robot-assisted therapy. Auton Robot 2003; 15: 7-20.

4. Burgar CG, Lum PS, Shor M, et al. Rehabilitation of upper limb dysfunction in chronic hemiplegia: robot-assisted movements vs. conventional therapy. Arch Phys Med Rehab 1999; 80: 1121.

5. Loureiro R, Amirabdollahian F, Topping M, et al. Upper limb robot mediated stroke therapy - GENTLE/s approach. Auton Robot 2003; 15: 35-51.

6. Lo HS and Xie SQ. Exoskeleton robots for upper-limb rehabilitation: state of the art and future prospects. Med Eng Phys 2012; 34: 261-268.

7. Kawasaki H, Ito S, Ishigure Y, et al. Development of a hand motion assist robot for rehabilitation therapy by patient self-motion control. In: Proceedings of the IEEE international conference on rehabilitation robotics, Noordwijk, 13-15 June 2007, pp.234-240. New York: IEEE.

8. Gupta A and O'Malley MK. Design of a haptic arm exoskeleton for training and rehabilitation. IEEE/ASME T Mech 2006; 11: 280-289.

9. Pehlivan AU, Rose C and O'Malley MK. System characterization of RiceWrist-S: a forearm-wrist exoskeleton for upper extremity rehabilitation. In: Proceedings of the 2013 IEEE international conference on rehabilitation robotics, Seattle, WA, 24-26 June 2013, pp.1-6. New York: IEEE.

10. Ragonesi D, Agrawal S, Sample W, et al. Series elastic actuator control of a powered exoskeleton. In: Proceedings of the 2011 annual international conference of the IEEE engineering in medicine and biology society, Boston, MA, 30 August-3 September 2011, pp.3515-3518. New York: IEEE.

11. Martinez JA, Ng P, Lu S, et al. Design of Wrist Gimbal: a forearm and wrist exoskeleton for stroke rehabilitation. In: Proceedings of the IEEE international conference on rehabilitation robotics, Seattle, WA, 24-26 June 2013, pp.1-6. New York: IEEE.

12. Galiana I, Hammond FL, Howe RD, et al. Wearable soft robotic device for post-stroke shoulder rehabilitation: identifying misalignments. In: Proceedings of the IEEE/ RSJ international conference on intelligent robots and systems, Vilamoura, 7-12 October 2012, pp.317-322. New York: IEEE.

13. Gopura RARC, Kiguchi K and Li Y. SUEFUL-7: a 7DOF upper-limb exoskeleton robot with muscle-modeloriented EMG-based control. In: Proceedings of the IEEE/RSJ international conference on intelligent robots and systems, St. Louis, MO, 10-15 October 2009, pp.1126-1131. New York: IEEE.

14. Otsuka T, Kawaguchi K, Kawamoto H, et al. Development of upper-limb type HAL and reaching movement for meal-assistance. In: Proceedings of the IEEE international conference on robotics and biomimetics, Phuket, Thailand, 7-11 December 2011, pp.883-888. New York: IEEE.

15. Hasegawa $Y$ and Oura S. Exoskeletal meal assistance system (EMAS II) for progressive muscle dystrophy patient. In: Proceedings of the IEEE international conference on rehabilitation robotics, Zurich, 29 June-1 July 2011, pp.16. New York: IEEE.

16. Rosen $\mathrm{J}$ and Perry JC. Upper limb powered exoskeleton. Int J Hum Robot 2007; 4: 529-548.

17. Aggogeri F, Borboni A and Pellegrini N. Jerk trajectory planning for assistive and rehabilitative mechatronic devices. Int Rev Mech Eng 2016; 10: 543-551. 
18. Ivanova G, Bulavintsev S, Ryu J-H, et al. Development of an exoskeleton system for elderly and disabled people. In: Proceedings of the international conference on information science and applications, Jeju Island, South Korea, 26-29 April 2011, pp.1-7. New York: IEEE.

19. Burgar CG, Lum PS, Shor PC, et al. Development of robots for rehabilitation therapy: the Palo Alto VA/Stanford experience. J Rehabil Res Dev 2000; 37: 663-673.

20. Wu TM, Wang SY and Chen DZ. Design of an exoskeleton for strengthening the upper limb muscle for overextension injury prevention. Mech Mach Theory 2011; 46: 1825-1839.

21. Frisoli A, Rocchi F, Marcheschi S, et al. A new forcefeedback arm exoskeleton for haptic interaction in virtual environments. In: Proceedings of the Eurohaptics conference and symposium on haptic interfaces for virtual environment and teleoperator systems, Pisa, 18-20 March 2005, pp.195-201. New York: IEEE.

22. Papadopoulos E and Patsianis G. Design of an exoskeleton mechanism for the shoulder joint. In: Proceedings of the 12th world congress in mechanism and machine sciences, Besancon, 18-21 June 2007, pp.1-6. Poland: IFToMM.

23. Johnson GR, Carus DA, Parrini G, et al. The design of a five-degree-of-freedom powered orthosis for the upper limb. Proc IMechE, Part H: J Engineering in Medicine 2001; 215: 275-284.

24. Pignolo L, Dolce G, Basta G, et al. Upper limb rehabilitation after stroke: ARAMIS a "robo-mechatronic" innovative approach and prototype. In: Proceedings of the IEEE RAS EMBS international conference on biomedical robotics and biomechatronics, Rome, 24-27 June 2012, pp.1410-1414. New York: IEEE.

25. Sarakoglou I, Tsagarakis NG and Caldwell DG. Occupational and physical therapy using a hand exoskeleton based exerciser. In: Proceedings of the IEEE/RSJ international conference on intelligent robots and systems, Sendai, Japan, 28 September-2 October 2004, vol. 3, pp.2973-2978. New York: IEEE.

26. Carignan C, Liszka M and Roderick S. Design of an arm exoskeleton with scapula motion for shoulder rehabilitation. In: Proceedings of the 12th international conference on advanced robotics, Seattle, WA, 18-20 July 2005, pp.524-531. New York: IEEE.

27. Mao Y and Agrawal SK. Design of a cable-driven arm exoskeleton (CAREX) for neural rehabilitation. IEEE T Robot 2012; 28: 922-931.

28. Gopura RARC, Bandara DSV, Kiguchi K, et al. Developments in hardware systems of active upper-limb exoskeleton robots: a review. Robot Auton Syst 2016; 75: 203-220.

29. Ruiz AF, Forner-Cordero A, Rocon E, et al. Exoskeletons for rehabilitation and motor control. In: Proceedings of the IEEE/RAS-EMBS international conference on biomedical robotics and biomechatronics, Pisa, 20-22 February 2006, pp.601-606. New York: IEEE.

30. Benitez LMV, Tabie M, Kirchner EA, et al. Exoskeleton technology in rehabilitation: towards an EMG-based orthosis system for upper limb neuromotor rehabilitation. J Robot 2013; 2013: 610589.

31. Ball SJ, Brown IE and Scott SH. A planar 3DOF robotic exoskeleton for rehabilitation and assessment. In:
Proceedings of the 29th annual international conference of the IEEE engineering in medicine and biology society, Lyon, 22-26 August 2007, pp.4024-4027. New York: IEEE.

32. Rahman MH, Ouimet TK, Saad M, et al. Dynamic modeling and evaluation of a robotic exoskeleton for upperlimb rehabilitation. Int J Inform Acquisit 2011; 8: 83-102.

33. Gopura RARC, Bandara DSV, Gunasekara JMP, et al. Recent trends in EMG-based control methods for assistive robots. In: Turker $\mathrm{H}$ (ed.) Electrodiagnosis in new frontiers of clinical research. Rijeka: InTechOpen, 2013, pp.237-268.

34. Lenzi T, De Rossi S, Vitiello N, et al. The neuro-robotics paradigm: NEURARM, NEUROExos, HANDEXOS. In: Proceedings of the annual international conference of the IEEE engineering in medicine and biology society, 2009 (EMBC 2009), Minneapolis, MN, 3-6 September 2009, vol. 2009, pp.2430-2433. New York: IEEE.

35. Ugurlu B, Nishimura M, Hyodo K, et al. A framework for sensorless torque estimation and control in wearable exoskeletons. In: Proceedings of the 12th IEEE international workshop on advanced motion control, Sarajevo, 2527 March 2012, pp.1-7. New York: IEEE.

36. Wolbrecht ET, Chan V, Reinkensmeyer DJ, et al. Optimizing compliant, model-based robotic assistance to promote neurorehabilitation. IEEE T Neur Sys Reh 2008; 16: 286-297.

37. Gunasekara JMP, Gopura RARC, Jayawardena TSS, et al. Dexterity measure of upper limb exoskeleton robot with improved redundancy. In: Proceedings of the 8th IEEE international conference on industrial and information systems, Peradeniya, Sri Lanka, 17-20 December 2013, pp.548-553. New York: IEEE.

38. Oh S, Kong K and Hori Y. Design and analysis of forcesensor-less power-assist control. IEEE $T$ Ind Electron 2014; 61: 985-993.

39. Carmichael MG. A musculoskeletal model-based assistance-as-needed paradigm for assistive robotics, 2013, https://opus.lib.uts.edu.au/handle/10453/24075

40. Ott C, Mukherjee R and Nakamura Y. Unified impedance and admittance control. In: Proceedings of the IEEE international conference robotics and automation (ICRA), Anchorage, AK, 3-7 May 2010, pp.554-561. New York: IEEE.

41. Krebs HI, Hogan N, Aisen ML, et al. Robot-aided neurorehabilitation. IEEE T Rehabil Eng 1998; 6: 75-87.

42. Frisoli A, Borelli L, Montagner A, et al. Arm rehabilitation with a robotic exoskeleleton in Virtual Reality. In: Proceedings of the IEEE 10th international conference on rehabilitation robotics (ICORR), Noordwijk, 13-15 June 2007, pp.631-642. New York: IEEE.

43. Micera S, Carrozza M, Guglielmelli E, et al. A simple robotic system for neurorehabilitation. Auton Robot 2005; 19: 271-284.

44. Culmer PR, Jackson AE, Makower S, et al. A control strategy for upper limb robotic rehabilitation with a dual robot system. IEEE/ASME T Mech 2010; 15: 575-585.

45. Craig JJ. Introduction to robotics: mechanics and control. Upper Saddle River, NJ: Pearson/Prentice Hall, 2005.

46. Concettoni $\mathrm{E}$ and Griffin MJ. The apparent mass and mechanical impedance of the hand and the transmission 
of vibration to the fingers, hand, and arm. J Sound Vib 2009; 325: 664-678.

47. Aggogeri F, Pellegrini $\mathrm{N}$ and Adamini R. Functional design in rehabilitation: modular mechanisms for ankle complex. Appl Bionics Biomech 2016; 2016: 9707801.

48. Serpelloni M, Tiboni M, Lancini M, et al. Preliminary study of a robotic rehabilitation system driven by EMG for hand mirroring. In: Proceedings of the 2016 IEEE international symposium on medical measurements and applications (MeMeA 2016), Benevento, 15-18 May 2016, article no. 7533730. New York: IEEE.

49. Takahashi CD, Der-Yeghiaian L, Le V, et al. Robotbased hand motor therapy after stroke. Brain 2008; 131: 425-437.

50. Tsao CC and Mirbagheri MM. Upper limb impairments associated with spasticity in neurological disorders. $J$ Neuroeng Rehabil 2007; 4: 45. 